\title{
Durable Continuous-Flow Mechanical Circulatory Support: State of the Art
}

\author{
Antonio Loforte *(D), Luca Botta (D), Silvia Boschi, Gregorio Gliozzi, Giulio Giovanni Cavalli, Carlo Mariani, \\ Sofia Martin Suarez and Davide Pacini
}

Citation: Loforte, A.; Botta, L.; Boschi, S.; Gliozzi, G.; Cavalli, G.G.; Mariani, C.; Martin Suarez, S.; Pacini, D. Durable Continuous-Flow Mechanical Circulatory Support: State of the Art. Hearts 2021, 2 , 127-138. https://doi.org/10.3390/ hearts2010010

Received: 19 January 2021

Accepted: 9 February 2021

Published: 12 February 2021

Publisher's Note: MDPI stays neutral with regard to jurisdictional claims in published maps and institutional affiliations.

Copyright: (C) 2021 by the authors Licensee MDPI, Basel, Switzerland. This article is an open access article distributed under the terms and conditions of the Creative Commons Attribution (CC BY) license (https:// creativecommons.org/licenses/by/ $4.0 /)$.
Division of Cardiac Surgery, IRCCS Azienda Ospedaliero-Universitaria di Bologna, 40138 Bologna, Italy; luca.botta@aosp.bo.it (L.B.); kk.slivy@gmail.com (S.B.); greg.gliozzi@hotmail.it (G.G.); giuliogiovannicavalli@gmail.com (G.G.C.); carlo_mariani@outlook.com (C.M.); docsofi74@hotmail.com (S.M.S.); davide.pacini@unibo.it (D.P.)

* Correspondence: antonioloforte@yahoo.it; Tel.: +39-05-1214-9043; Fax: +39-051-345-990

Abstract: Implantable mechanical circulatory support (MCS) systems for ventricular assist device (VAD) therapy have emerged as an important strategy due to a shortage of donor organs for heart transplantation. A growing number of patients are receiving permanent assist devices, while fewer are undergoing heart transplantation (Htx). Continuous-flow (CF) pumps, as devices that can be permanently implanted, show promise for the treatment of both young and old patients with heart failure (HF). Further improvement of these devices will decrease adverse events, enable pulse modulation of continuous blood flow, and improve automatic remote monitoring. Ease of use for patients could also be improved. We herein report on the current state of the art regarding implantable CF pumps for use as MCS systems in the treatment of advanced refractory HF.

Keywords: advanced heart failure; left ventricular assist device; biventricular assist device; rotary blood pumps; technology

\section{Introduction}

Given the increasing shortage of donor organs, implantable mechanical circulatory support (MCS) systems for ventricular assist device (VAD) therapy have emerged as an essential element of treatment [1-24]. These devices are installed permanently in many patients, and fewer are now undergoing heart transplantation (Htx).

During waiting periods for donor availability, the VAD system provides additional support as well as improves the physiology of the heart. Patients supported by VADs can be discharged from intensive care units or hospitals because VADs are mostly intracorporeal and improve quality of life compared with short-term devices. Using VADs as destination therapy (DT) is now an acceptable as well as a feasible therapy for the patients of end-stage heart failure (HF) who cannot qualify for Htx [1-24].

\section{The History, Clinical Requirement for, and Technology of VADs}

The challenging development of VAD therapy began in 1988 [8,9]. The first continuousflow pump, which was designated as a Hemopump, was used for circulatory support in patients suffering from cardiogenic shock [8,9]. The Hemopump is a percutaneous catheter-mounted VAD. In contrast to pneumatic systems, the Hemopump pumps blood continuously. The device does not cause hemolysis, despite the high number of revolutions per minute (rpms) of its operating impeller. This finding prompted the MCS scientific community to focus on the adoption of CF-VADs in the second half of the 1980s [8,9]. The advantages of CF-VADs over pulsatile and paracorporeal devices is that they are silent, miniaturized, and reduce trauma during surgery, allowing patients to gain a relatively unrestricted life [6-12]. The first human insertion of an implantable CF-VAD, the MicroMed 
DeBakey I, was performed in Berlin on November 11, 1998 in a patient with end-stage heart failure (HF), who was supported for 47 days until his exitus [8,9].

Advanced medical therapy, last-generation pacemakers, and defibrillators have changed the clinical evolution of HF $[9,11,12,22-24]$. However, $0.5-5 \%$ of patients are refractory to any optimized medical therapy and develop advanced HF. Analyses from the United States of America (USA) suggest that 250,000-300,000 patients under the age of 75 years suffer from advanced systolic HF (defined as New York Heart Association (NYHA class IIIb-IV)) [1,3,22,23]. In Europe, 500,000 patients are likely to be suffering from $\mathrm{HF}$ $[6,9-12,24]$. The prognosis for advanced HF is poor; the 1 -year mortality rate is $>25 \%$ for class III-IV outpatients and exceeds $50 \%$ for class IV patients. While conservative care is the primary strategy for patients with advanced age and important comorbidities, advanced replacement therapies, such as Htx or a left ventricular assist device (LVAD), are promising options for other cases. Htx is a well-accepted strategy option for many patients, but the lack of donor organs remains a severe limitation. Long-term LVADs have been used for several years in both acute and chronic refractory HF, mostly as a bridge to Htx. Technology improvements, together with the shortage of donors, have recently led to the adoption of LVADs in a much extended range of patients $[6-12,23,24]$.

\subsection{Pumps}

Contemporary CF-LVADs are electrically driven via a percutaneous driveline connected to a small computer (controller) and an external energy source (batteries) [6-12] (Figure 1).
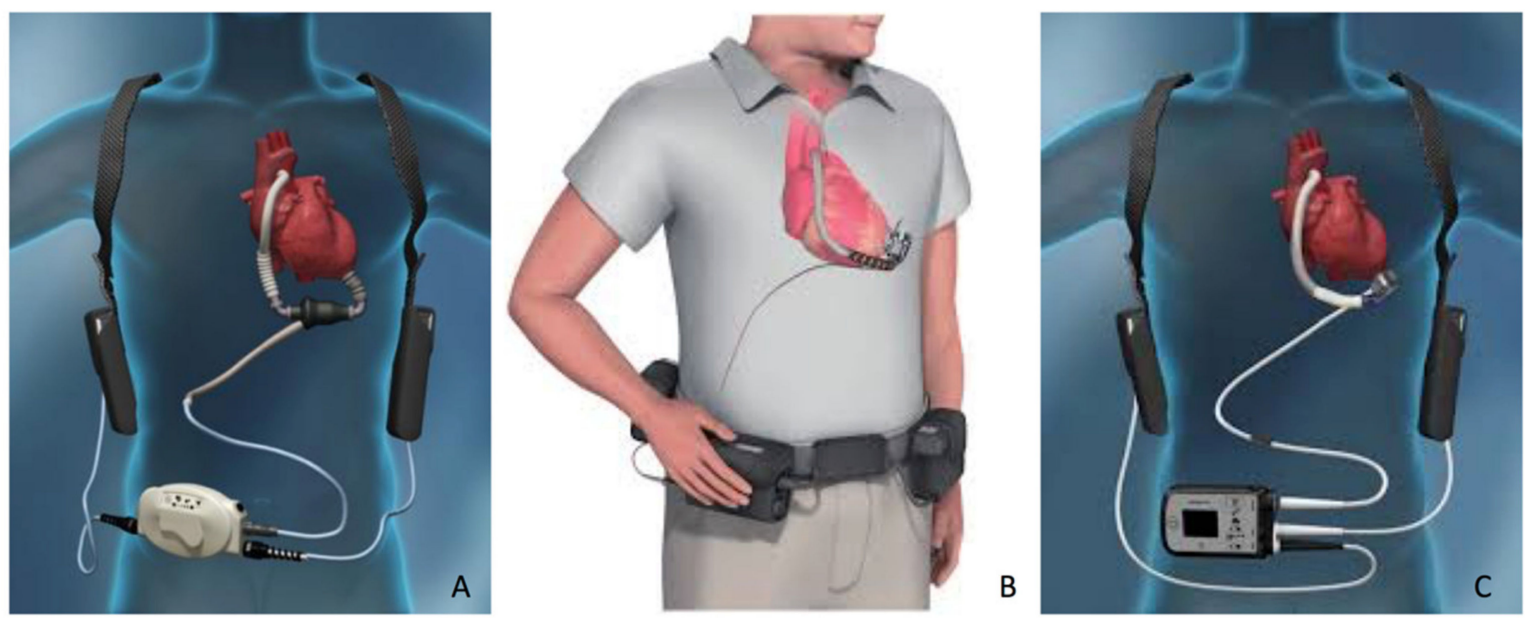

Figure 1. The most adopted continuous-flow left ventricular assist devices settings. (A) HeartMate II, (C) HeartWare HVAD, and (B) HeartMate 3.

In recent years, the majority of patients treated with a long-term LVAD received a CF system, i.e., a radial pump such as the HeartWare HVAD (Medtronic), or an axial-flow pump such as the HeartMate II (Abbott) [5-15]. Recently, a new generation of magnetically levitated radial pumps (HeartMate 3; Abbott) received Conformité Européenne (CE) approval and became available in Europe [5,16-21]. Generally, these pumps unload the heart by pumping blood from the left ventricle to the ascending aorta $[7,9,11,12]$.

Implantable CF-LVADs generate up to $10 \mathrm{~L} / \mathrm{min}$ of $\mathrm{CF}$, and most patients have no evident arterial pulse peripherally [6-12]. The HeartMate 3 has software that varies the pump rpms and creates an artificial pulse every $2 \mathrm{~s}$, which facilitates the washing of the blood-contacting surfaces of the system $[16,17]$. While old-generation pulsatile pumps had a limited durability of around 2 years, CF devices can currently last over 10 years.

In the USA, implantation rates are collected by the Interagency Registry for Mechanically Assisted Circulatory Support (INTERMACS) registry [1,3-5,23]. Currently, over 
2500 devices are implanted in North America every year. Similarly, 2000 pumps are estimated to be implanted annually in Europe [2,11,12,24].

\subsection{Axial Flow}

Axial-flow CF-LVADs have an impeller that rotates at speeds between 6000 and $15,000 \mathrm{rpm}$ to circulate blood flow [6-12]. Due to their miniaturization, the majority of systems are second-generation pumps; however, third-generation technology has also been utilized. The impeller peripheral velocity is higher than that for radial-type devices and leads to relatively high shear force. Additionally, the need for stationary guide vanes and an impeller suspension may facilitate clotting formation in areas of stasis.

All axial-flow pumps provide full circulatory support $[6-12,23,24]$. Thoratec Corporation, Jarvik Heart, MicroMed Cardiovascular, and Berlin Heart are the main companies manufacturing these systems, and all have obtained CE approval. Since the initiation of clinical trials in July 2000, the HeartMate II (Thoratec) (Figure 1) has been implanted in up to 10 times more patients than any other CF device ( $>6000$ patients worldwide).

\subsection{HeartMate II}

The HeartMate II is a second-generation implantable axial-flow pump that provides full circulatory support (up to $10 \mathrm{~L} / \mathrm{min}$ ) to HF patients [6-12] (Figure 1). This device is approximately the size of a D-Cell battery, weighs $375 \mathrm{~g}$, and incorporates an electromagnetic DC brushless motor for rotation in the setting of a "dual-cup bearing supported impeller" [11,12]. The device can spin at speeds of $6000-15,000 \mathrm{rpm}$. Changes in the pivot bearing area have decreased the risk of thrombus formation $[6-12,23,24]$. The HeartMate II gained approval from the Food and Drug Administration (FDA) for bridge to transplantation (BTT) in 2008 and destination therapy (DT) in 2010 [6-12].

\subsection{Radial Flow}

Despite being slightly larger in size than axial-flow systems, radial-flow (centrifugal) pumps are suitable for long-term cardiac assistance due to their lower rotational speed, higher hydraulic efficiency, lack of stationary vanes, and more anatomically suitable shape [6-12]. Due to their rotor design and increased surface area, these pumps can get third-generation bearing technology for the full suspension of their impeller using hydrodynamic or magnetic forces. This drastically increases the device lifetime.

All radial-flow systems provide full circulatory support. Devices have been developed by WorldHeart, Terumo, Medtronic (HeartWare), and Abbott (Thoratec) that have either received CE approval in Europe or FDA approval in the USA for short- to long-term usage, based on clinical trials. HeartWare HVAD (Medtronic) and HeartMate 3 (Abbott) are being used increasingly often, with implantations performed using these devices already surpassing those using all previous rotary devices [5-21,23,24].

\subsection{HeartWare HVAD}

The HeartWare HVAD (Medtronic) is a third-generation radial-flow pump implanted in the pericardial space [5-15,19-21] (Figure 1). The HVAD drains blood from an integrated inflow cannula inserted directly into the ventricular cavity. Initially designed for left ventricular assistance, the device has been also modified for biventricular assistance.

The impeller is suspended via a combination of magnetic and hydrodynamic forces [11-15]. The device is the most miniaturized (145 g) radial-flow pump. The motor [11-15] rotates the impeller at a speed of $2400 \mathrm{rpm}$, delivering blood at a rate of up to $10 \mathrm{~L} / \mathrm{min}$. Speeds between 1800 and $4000 \mathrm{rpm}$ are set [11-15]. The lower speed limit provides the generation of a hydrodynamic force, which maintains stable impeller levitation.

A ceramic-titanium blood-contacting surface is used to prevent clotting formation. Clinical trials of the HVAD device started in 2008. CE approval was obtained in 2009, while FDA approval for BTT was obtained in 2012 and for DT in 2017 [5-15,19-21,23,24]. 


\subsection{HeartMate 3}

The HeartMate 3 (Abbott) is a new radial-flow LVAD (Figure 1) that is intended to provide full hemodynamic support to patients with advanced HF [5-12,16-21]. The device is manufactured for the intrapericardial position, with the inflow cannula inserted into the left ventricle and the outflow graft anastomosed to the ascending aorta. A fully magnetically levitated rotor with large "blood-flow channels" minimizes shear force and reduces negative effects on blood components [5-12,16-21]. This impeller design avoids the need for mechanical bearings, thus minimizing wear on the moving pump components and the generation of heat. The LVAD internal surfaces are textured with titanium microspheres to avoid thrombogenicity. The pump rotor changes speed every $2 \mathrm{~s}$ to generate pulsatile flow. The pump operates at rotor speeds in the range of 3000-9000 rpm, and the maximum flow rate is $10 \mathrm{~L} / \mathrm{min}$.

CE approval for usage was granted in 2015 following a clinical trial completed on 27 November 2014. The HeartMate 3 was approved for both short- and long-term support following a USA clinical trial initiated in September 2014 [5-12,16-21,23,24]. FDA approval for use for BTT was granted in 2016 and for DT in 2018.

\section{Surgical Issues}

The miniaturization of the pumps described above and their placement within the pericardial space eliminate the need for an abdominal pump pocket [6-12]. Less surgical trauma and associated bleeding shortens the recovery time and reduces the likelihood of infectious complications, which often occur as a result of blood transfusions and prolonged intensive care [23-32].

The most recent American Society for Thoracic Surgery (AATS) and International Society for Heart and Lung Transplantation (ISHLT) guidelines [23] and the 2019 European Association for Cardiothoracic Surgery (EACTS) expert consensus document [24] recommend inflow cannula placement into the left ventricular anterior wall and outflow placement on the lateral ascending aorta tract.

A less invasive outflow line is through the transverse sinus; this is commonly used for BTT [31] and prevents positional changes of the LVAD after sternal closure. Moreover, it enables easier and safer re-entry during Htx.

In cases of heavy calcification, proximal graft anastomosis, or pseudoaneurysms, the ascending aorta is contraindicated as the outflow graft anastomosis site. Alternative sites, such as the descending thoracic aorta, supraceliac abdominal aorta, innominate artery, and subclavian arteries, have yielded acceptable results [23-32].

Miniaturized third-generation centrifugal pumps, HeartWare HVAD (Medtronic) and HeartMate 3 (Abbott), are currently the most commonly used systems. Their design has allowed clinicians to pioneer several less invasive implantation techniques applicable to a wide range of clinical scenarios $[5,23-25,27]$.

\section{Outcomes}

\subsection{Survival}

Survival after CF-LVAD implantation has improved in recent years. A recent analysis of the INTERMACS registry of CF-LVADs revealed 1- and 2-year survival rates of $80 \%$ and $70 \%$, respectively $[1,3-5,33]$. Slightly lower survival rates were reported based on analysis of the European Registry for Patients with Mechanical Circulatory Support (EUROMACS) registry $(73 \%, 63 \%$, and $61 \%$ at 1,2 , and 3 years, respectively) [2]. In the ENDURANCE DT randomized trial $(n=446)$, the 2-year survival rates with HVAD and HeartMate II were $60 \%$ and $68 \%$, respectively $(p=0.17)[1,3-5,11,13-15,34]$. Data on long-term outcomes are sparse, and only those from the DT category can be considered meaningful because most BTT patients are censored due to heart transplantation (Htx) with long-term follow-up. However, a recent postmarket analysis of 254 patients treated with an HVAD (BTT and DT) revealed a 5-year survival rate of $59 \%[1,3-5,11,13-15,34]$. 
Outcomes will improve more and more with the development of novel LVAD systems. Recently published results from a study of 50 patients implanted with the HeartMate 3 , following which CE approval was granted, revealed a 6-month survival rate of $92 \%$. For the first 294 patients randomized to the recent MOMENTUM trial, which compared outcomes between the HeartMate 3 and HeartMate II, the respective 6-month survival rates were $89 \%$ and $87 \%[33,35,36]$.

In a 2-year study of 366 patients, 190 were assigned to a centrifugal-flow pump group and 176 to an axial-flow pump group [33,35,36]. Two-year survival was 79.5\% ( $n=151$ patients) in the centrifugal-flow pump group and $60.2 \%$ ( $n=106$ patients) in the axial-flow pump group. Reoperation due to pump malfunction was less frequent in the centrifugal-flow pump group compared to the axial-flow pump group $(1.6 \% \mathrm{vs} .17 .0 \%$; $p<0.001)$. The rates of death and debilitative stroke were similar between the two groups, but the overall rate of stroke was lower in the centrifugal-flow pump group compared to the axial-flow pump group $(10.1 \%$ vs. $19.2 \%$; $p=0.02)$.

Schramm et al. [19] compared 79 HVAD and 79 HeartMate 3 patients and found no difference in survival. However, driveline wound infection was more common in the HeartMate 3 cohort. Mueller et al. [20] matched 100 HVAD and 100 HeartMate 3 patients and found no difference in survival. However, driveline wound infection was again more common in the HeartMate 3 cohort, while the HVAD cohort had a higher rate of cerebral stroke. The incidence of hemocompatibility-related adverse events, however, was significantly higher in the HVAD group (113 points (corresponding to 1.28 events per patient-year) vs. 69 points (corresponding to 0.7 events per patient-year), $p<0.001$ ). Itzhaki Ben Zadok et al. [21] matched 25 HVAD and 26 HeartMate 3 patients and found no difference in survival. However, the risk of stroke and pump thrombosis in the HeartMate 3 group was lower.

A recent EUROMACS propensity score analysis matched 359 HVAD and 359 HeartMate 3 patients (personal communication of Dr. Potapov during the 2020 virtual annual EACTS meeting; https: / / www.eacts.org/resources/eacts-library/ (accessed on 10 May 2020)) and found no difference in survival [2]. The proportion of patients free from major adverse events after two years was similar between the groups $(44.2 \%$ vs. $47.9 \%, p=0.226)$. However, overall, HeartMate 3 patients showed poorer health.

In summary, the HVAD and HeartMate 3 pumps have similar mid-term survival rates and complication profiles $[5,11,12,19-21,33]$. Both of these centrifugal pumps are associated with better patient outcomes than second-generation axial-flow pumps (Figure 2) [1-18].

The HVAD is a versatile and reliable pump that can be implanted in patients differing widely in terms of clinical characteristics and shows good long-term results [25-32]. The HVAD was the first device to be placed inside the pericardium via less invasive surgery (LIS) [24-27]. The LATERAL trial [28] was a multicenter, prospective, nonrandomized, single-arm study utilizing data from 144 patients enrolled in the INTERMACS database, drawn from 26 centers in the USA and Canada. The LATERAL trial validated sternalsparing approaches for intrapericardial device (HVAD) implantation in a selected BTT cohort; overall survival and freedom from adverse events were superior compared to full sternotomy access. Many single-center studies also reported better survival and lower perioperative complication rates [23-32]. Although HeartMate 3 (Abbott) is bulkier than other devices, it is effective for LIS strategies [24-27,29,30].

Independent of the surgical implantation approach, different risk factors for early mortality after CF-LVADs implantation have been identified, including advanced age, female gender, high body mass index (BMI), INTERMACS level 1-2, renal failure, liver failure, and the need for concomitant cardiac procedures [1-6,23,24,36]. Full acknowledgment of these factors, along with optimized pump technologies and improved medical care, will provide a better prognosis for such a delicate patient population in the near future. 


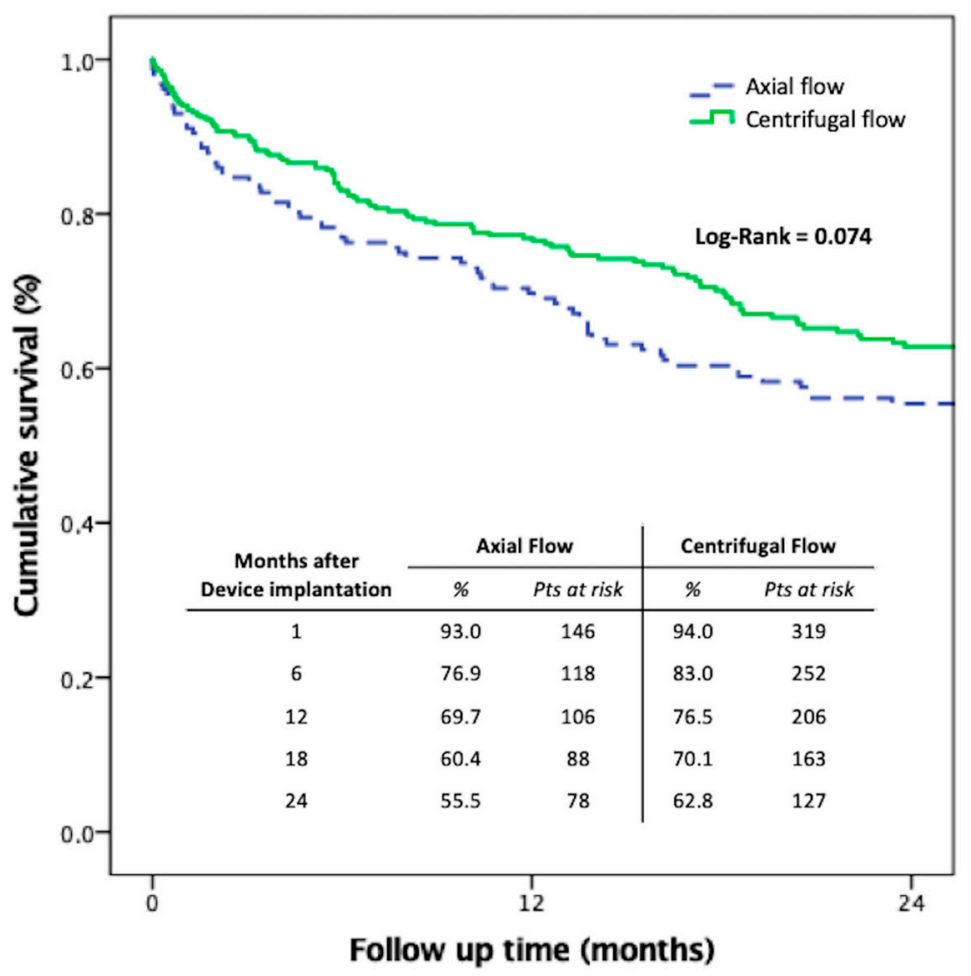

Figure 2. Kaplan-Meier survival analysis of centrifugal versus axial-flow pump cohorts by the Multicenter Italian Study on Radial Mechanically Assisted Circulatory Support (MIRAMACS) registry. The results are comparable with the reported outcomes of other registries reported [1-12,33].

\subsection{Adverse Events}

\subsubsection{Bleeding}

Bleeding is a frequently reported adverse event and is often described to differentiate early or late surgical from nonsurgical bleeding. The proportion of patients experiencing bleeding requiring surgery reported in the literature varies from $0 \%$ to $45 \%$ [1-12,19-21,23,24,33,36]. Reasons for such variance include differences in surgical technique, postoperative anticoagulant regimens, and patient risk factors. Examining the studies that reported event rates the single- and multicenter case series reported rates ranging from 0.16 to 0.59 $[1-12,19-21,23,24,33,36]$.

CF-LVAD support has also been associated with the development of a bleeding diathesis that manifests as late bleeding, predominantly gastrointestinal bleeding (GIB). Multicenter studies report an incidence of GIB ranging from 6\% to 35\% [1-12]. Examining studies that reported this outcome as an event rate, this outcome occurs with a frequency of between 0.14 and 0.71 events per patient-year [1-12,19-21,23,24,33,36].

\subsubsection{Neurological Events}

Neurological events including ischemic stroke, hemorrhagic stroke, and transient ischemic attack (TIA) are relatively common after CF-LVAD implantation and can be a cause of significant morbidity and mortality. The risk of ischemic and hemorrhagic stroke ranged from $0 \%$ to $26 \%$ and $0 \%$ to $16 \%$, respectively [1-12,19-21,23,24,33,36]. Follow-up in these studies ranged from approximately six months to two years, with a higher risk of stroke generally associated with prolonged duration of device support. This observation is in line with the findings of the fifth IN-TERMACS annual report, which demonstrated the $6-, 12-$, and $24-$ month risk of stroke to be $7 \%, 11 \%$, and $17 \%$, respectively $[1,33]$.

\subsubsection{Infection}

Despite the smaller diameter power cable compared to the first-generation pulsatile LVAD systems, the CF-LVAD driveline remains a source of entry for bacteria with the 
potential for developing driveline infection (DLI), pump pocket infection, or sepsis. According to the literature, DLIs were one of the most common complications after LVAD implantation, occurring in $5 \%$ to $55 \%$ of patients $[1-12,19-21,23,24,33,36]$. Despite the high rates of DLI, pump pocket infection rates are much lower, ranging from $1 \%$ to $22 \%$. Reports of sepsis were almost as varied as those of DLI, with rates of sepsis ranging from $3 \%$ to $33 \%$. When reported in events per patient-year DLI (0.2 to 1.27) was more common than sepsis (0.1 to 0.41$)$ and pump pocket infection (0.01 to 0.22$)$ [1-12,19-21,23,24,33,36].

\subsubsection{Pump Thrombosis}

The incidence of pump thrombosis requiring device exchange should be not underweighted. They reported a risk of between $2 \%$ and $11 \%$ of LVAD recipients $[1-12,19-21,23,24,33,36]$. This is still significantly less than the nearly $50 \%$ of patients implanted with the first-generation HeartMate XVE who experienced device exchange due to malfunction or infection at 18 months [1-12]. Expressed as the number of events per patient-year this was a relatively uncommon occurrence (less than 0.07 events per patient-year) [1-12,19-21,23,24,33,36].

Routine monitoring of hemolysis markers is recommended to provide early detection of pump thrombosis $[23,24]$. Fully magnetically levitated systems may reduce this risk, although further scrutiny and long-term follow-up data are still needed for confirmation $[16,17,19-21,33,35,36]$.

\subsubsection{Right Heart Failure}

Right heart failure has (RHF) been associated with poorer outcomes and increased short-term mortality [1-12,19-21,23,24,33,36]. In the literature, RHF requiring prolonged inotropic support is present in $2 \%$ to $31.7 \%$ of patients, while RHF requiring placement of a right ventricular assist device (RVAD) is reported in $2.9 \%$ to $40 \%$ of patients $[1-12,19-21,23,24,33,36]$. Current studies on last-generation centrifugal pumps reveal a requirement for prolonged inotropic support and RVAD placement of $2 \%$ to $24 \%$ and $4 \%$ to $22 \%$, respectively $[33,36]$.

\section{Discussion}

When CF-LVAD treatment was first introduced [8,9], it was unclear how the human organism would react to a completely different circulation pattern. Since then, however, reports have shown that all types of CF-LVADs could achieve acceptable physiological conditions, such that they can be used in several clinical scenarios [1-12,28,33].

In contrast to previously used pulsatile pumps, CF-LVADs have allowed patients to lead quite a normal life and participate in several social activities owing to their quiet operation and lack of a large external drive unit [6-12].

Moreover, the transition to CF devices has been accelerated by the results of studies demonstrating mechanical problems-thrombosis, pump failure, system membrane rupture-that occurred more frequently in pulsatile devices with consequent poor outcomes $[1-12,19-21,33]$.

The wide acceptance of CF-LVADs by patients, physicians, and the general public has led to their routine use for treating HF patients. CF-LVADs have fulfilled the desires of artificial heart developers. However, certain consequences of continuous blood flow still need to be addressed by clinicians [1-12] as hospital readmissions incidence after LVAD implantation is still high, ranging from 1.3 to 2.6 hospitalizations per patient-year $[1-12,19-21,23,24,33]$.

Special methods have been developed for early recognition of dangerous device malfunctions, such as driveline lesions and abnormal power demands [6-12]. New pump software and log-file analysis methods can detect the signal alterations and can predict serious adverse events or abnormal circulation, thus aiding clinicians in the management of their patients [6-12]. 
The deployment of highly trained teams consisting of surgeons, cardiologists, anesthesiologists, perfusionists, and specialized nurses has been vital for reducing complications after CF-LVAD implantation $[9,11,12]$.

One of the major obstacles in current LVAD therapy is driveline infections [1-12]. While wireless technologies are now part of daily life, running an LVAD wirelessly is currently unfeasible. Elimination of the driveline as a source of infection in VADs powered transcutaneously will make the devices far safer [37,38].

The two most innovative systems to avoid cable infections are: (1) the transcutaneous energy transmission (TET) system, which transfers energy via two coils, one under and the other over the skin; and (2) the Jarvik 2000 LVAD (Jarvik Heart Inc., New York, NY, USA), in which a retroauricular titanium pedestal is placed on the skull, thus providing a low infection rate $[39,40]$. The TET system was used in conjunction with the Arrow LionHeart (Arrow International, PA) as a pulsatile LVAD in an individual who survived for 3.5 years without skin complications [37]. The same concept, even if with different technology, has been applied to the Jarvik 2000 LVAD (Jarvik Heart Inc., NY) associated with the Leviticus-Cardio system (Leviticus-Cardio Ltd., Petach Tikva, Israel) [38] as the first wireless coplanar energy transfer system used in humans.

Although primarily indicated for left ventricular failure, VADs have become utilized in a biventricular set up to combat RHF following LVAD implantation (Figure 3) [1-12,24,33,41-44].

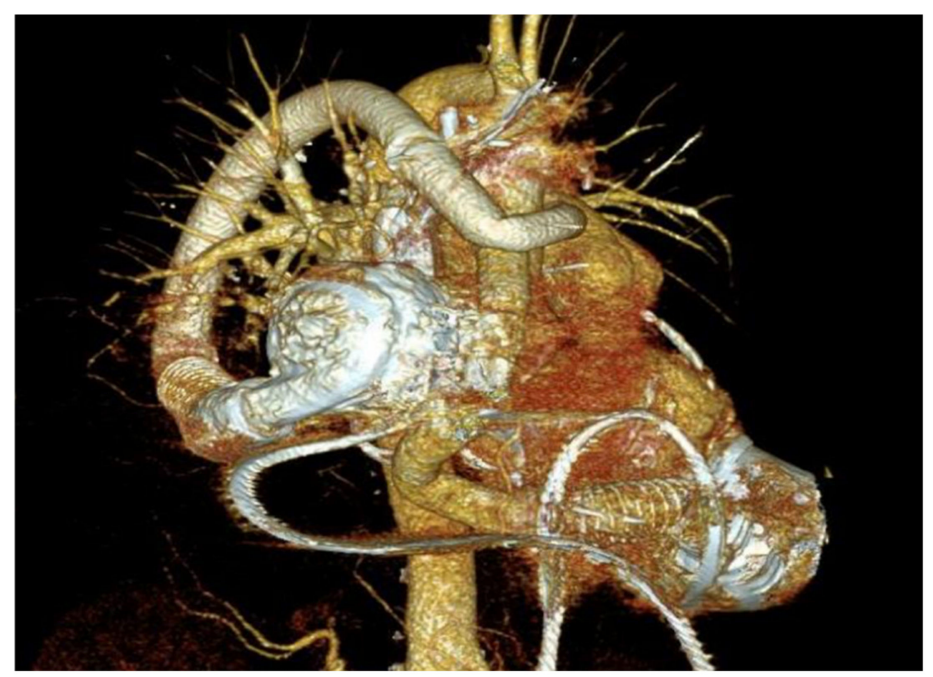

Figure 3. Three-dimensional (3D)-reconstructed computed tomography (CT) scan of an implantable centrifugal biventricular assist device (BiVAD) support.

However, a permanent and on-label long-term mechanical solution for RVADs does not currently exist. Hence, clinicians have resorted to using LVADs in the right-sided position. An INTERMACS report published in 2017 recorded a total of 22,866 mechanical support devices implanted from 2006-2016 [1-12,33]. Of these, 616 were continuous-flow BiVADs (CF-BiVADs) (2.7\%) and 349 were pulsatile BiVADs (1.5\%). The latest INTERMACS report showed that the proportion of CF-BiVADs dramatically replaced the use of pulsatile devices (3.9\% vs. $0.1 \%$, respectively), with BiVAD implantation composing $4.1 \%$ of all durable devices [1-12,33].

Long-term BiVAD patient survival is not consistently reported, ranging from 6 months to 12 months. This reflects the relatively low number of BiVAD recipients as well as the novel nature of CF devices in this configuration. Nonetheless, survival, when reported at 12 months, is a far less encouraging $57 \%$, significantly less than at 30 days [1-12,24,33,41-44]. 
This once again highlights how critically unwell this cohort is. BiVAD implantation confers double the risk of mortality compared with LVAD alone. Thus, the RHF and associated end-organ dysfunction may be the greatest contributor to the increased mortality.

The total artificial heart (TAH) remains a viable alternative to BiVAD implantation. Studies have shown no difference in outcome between TAH vs. BiVAD thus far $[1-12,24,41-44]$. However, it is also bulkier and more expensive, thus few centers have experience with its implantation and postoperative care compared with utilizing an additional LVAD. Furthermore, being a pulsatile device, it requires a large driver that contains a noisy compressor and is significantly limited in comparison with the BiVADs currently available. However, TAH provides a role in patients with refractory arrhythmias as well as those with restrictive cardiomyopathies where VAD placement would be complicated by small ventricular cavities [1-12,24].

According to the results mentioned herein, a CF-RVAD for an on-label BiVAD configuration is greatly in need [41-44].

To conclude, the percutaneous heart pump could be used in the future to minimize trauma from surgical implantation as a fully catheter-based axial-flow system with both transfemoral and transapical applications. These devices are currently under investigation but may ultimately demonstrate the utility of miniaturized CF-LVAD technology for both left and right ventricular support $[9,11,12]$.

\section{Conclusions}

Due to the rising population of advanced-stage HF patients and the limited availability of heart donors, durable VADs have become an effective strategy to provide a successful bridge until Htx, comfort cardiac recovery, or assist as DT for those who cannot qualify for Htx.

The innovation in device design such as miniaturized forms, minimally invasive approach for implantation, permanently implantable, enhancement in durability and efficacy of pumps, use of the smart system for monitoring, and the durability of batteries, fully automated devices are either in use or currently being evaluated for promising clinical results.

We have above discussed, in detail, how LVAD therapy developed from a novel idea into a feasible clinical option for an increasing number of patients. Furthermore, CF-LVAD systems are a highly feasible permanent therapeutic option, particularly for elderly patients, and are now being used routinely for treating HF. However, there is a need for smaller CF-LVADs with more durable components. Improved pump design should decrease rates of infection and thrombus formation, increase hemocompatibility, enable pulse modulation of continuous flow, ensure an automatic system monitoring through telemonitoring, and improve ease of use for patients.

The elimination of percutaneous lead and introduction of wireless energy transfer is the forthcoming demand for allowing the patient to pursue activities such as swimming and playing water sports or engage in contact sports, which are not suitable with currently available devices.

Studies on CF-BiVADs are promising [41-44], and future progress will also accommodate this small but delicate cohort of biventricular failure patients while awaiting definitive transplantation. A dedicated CF-BiVAD device would additionally reduce to a single driveline and controller, thus decreasing infection risk and improving quality of life.

Additionally, in the near future, CF-LVADs that can perform the functions of total artificial hearts are likely to be developed [41-44].

Author Contributions: Conceptualization: A.L.; methodology: A.L.; software: A.L., L.B., S.B., G.G., G.G.C., C.M., S.M.S., D.P.; validation: A.L., L.B., S.B., G.G., G.G.C., C.M., S.M.S., D.P.; formal analysis: A.L., L.B., S.B., G.G., G.G.C., C.M., S.M.S., D.P.; investigation: A.L., L.B., S.B., G.G., G.G.C., C.M., S.M.S., D.P.; resources: A.L., L.B., S.B., G.G., G.G.C., C.M., S.M.S., D.P.; data curation: A.L., L.B., S.B., G.G., G.G.C., C.M., S.M.S., D.P.; writing—original draft preparation: A.L.; writing-review and editing: A.L., L.B., S.B., G.G., G.G.C., C.M., S.M.S., D.P.; visualization: A.L.; supervision: D.P.; project 
administration: D.P.; funding acquisition: none. All authors have read and agreed to the published version of the manuscript.

Funding: This research received no external funding.

Conflicts of Interest: The authors declare no conflict of interest.

\section{References}

1. Kirklin, J.K.; Naftel, D.C.; Pagani, F.D.; Kormos, R.L.; Stevenson, L.W.; Blume, E.D.; Myers, S.L.; Miller, M.A.; Baldwin, J.T.; Young, J.B. Seventh INTERMACS annual report: 15,000 patients and counting. J. Hear. Lung Transplant. 2015, 34, 1495-1504. [CrossRef]

2. De Bya, T.M.M.H.; Schweigerb, M.; Waheedc, H.; Bergerd, F.; Hublerb, M.; Ozbarane, M.; Maruszewskif, B.; Napoleoneg, C.P.; Loforteh, A.; Meyns, B.; et al. The European Registry for Patients with Mechanical Circulatory Support (EU-ROMACS) of the European Association for Cardio-Thoracic Surgery (EACTS): Second report. Eur. J. Cardiothorac. Surg. 2018, 53, 309-316. [CrossRef]

3. Kirklin, J.K.; Xie, R.; Cowger, J.; de By, T.M.; Nakatani, T.; Schueler, S.; Taylor, R.; Lannon, J.; Mohacsi, P.; Gummert, J.; et al. Second annual report from the ISHLT Mechanically Assisted Circulatory Support Regis-try. J. Heart Lung Transplant. 2018, 37, 685-691. [CrossRef]

4. Stulak, J.M.; Davis, M.E.; Haglund, N.; Dunlay, S.M.; Cowger, J.A.; Shah, P.; Pagani, F.D.; Aaronson, K.D.; Maltais, S. Adverse events in contemporary continuous-flow left ventricular assist devices: A multi-institutional comparison shows significant differences. J. Thorac. Cardiovasc. Surg. 2016, 151, 177-189. [CrossRef]

5. Goldstein, D.J.; Meyns, B.; Xie, R.; Cowger, J.; Pettit, S.; Nakatani, T.; Netuka, I.; Shaw, S.; Yanase, M.; Kirklin, J.K. Third annual report from the ISHLT Mechanically Assisted Circulatory Support Regis-try: A comparison of centrifugal and axial continuous-flow left ventricular assist devices. J. Heart Lung Transplant. 2019, 38, 352-363. [CrossRef]

6. Potapov, E.V.; Krabatsch, T.; Ventura, H.O.; Hetzer, R. Advances in mechanical circulatory support: Year in review. J. Hear. Lung Transplant. 2011, 30, 487-493. [CrossRef]

7. Slaughter, M.S.; Rogers, J.G.; Milano, C.A.; Russell, S.D.; Conte, J.V.; Feldman, D.; Sun, B.; Tatooles, A.J.; Delgado, R.M.; Long, J.W.; et al. Advanced Heart Failure Treated with Continuous-Flow Left Ventricular Assist Device. N. Engl. J. Med. 2009, 361, 2241-2251. [CrossRef] [PubMed]

8. Alnajar, A.; Frazier, O. The State of Artificial Heart Therapy. Tex. Heart Inst. J. 2019, 46, 77-79. [CrossRef] [PubMed]

9. Hetzer, R.; Kaufmann, F.; Potapov, E.V.; Krabatsch, T.; Delmo Walter, E. Rotary Blood Pumps as Long-Term Mechanical Circulatory Support: A Review of a 15-Year Berlin Experience. Semin. Thoracic. Surg. 2016, 28, 12-23.

10. Potapov, E.V.; Loforte, A.; Weng, Y.; Jurmann, M.; Pasic, M.; Drews, T.; Loebe, M.; Hennig, E.; Krabatsch, T.; Koster, A.; et al. Experience with over 1000 Implanted Ventricular Assist Devices. J. Card. Surg. 2008, 23, 185-194. [CrossRef] [PubMed]

11. Gummert, J.F.; Haverich, A.; Schmitto, J.D.; Potapov, E.; Schramm, R.; Falk, V. Permanent implantable cardiac support systems. Dtsch. Aerzteblatt Int. 2019, 116, 843-848. [CrossRef] [PubMed]

12. Wiedemann, D.; Haberl, T.; Riebandt, J.; Simon, P.; Laufer, G.; Zimpfer, D. Ventricular Assist Devices—Evolution of Surgical Heart Failure Treatment. Eur. Cardiol. Rev. 2014, 9, 54-58. [CrossRef] [PubMed]

13. Aaronson, K.D.; Slaughter, M.S.; Miller, L.W.; McGee, E.C.; Cotts, W.G.; Acker, M.A.; Jessup, M.L.; Gregoric, I.D.; Loyalka, P.; Frazier, O.; et al. Use of an Intrapericardial, Continuous-Flow, Centrifugal Pump in Patients Awaiting Heart Transplantation. Circulation 2012, 125, 3191-3200. [CrossRef]

14. Slaughter, M.S.; Pagani, F.D.; McGee, E.C.; Birks, E.J.; Cotts, W.G.; Gregoric, I.; Frazier, O.H.; Icenogle, T.; Najjar, S.S.; Boyce, S.W.; et al. HeartWare ventricular assist system for bridge to transplant: Combined results of the bridge to transplant and continued access protocol trial. J. Heart Lung Transplant. 2013, 32, 675-683. [CrossRef] [PubMed]

15. Strueber, M.; O’Driscoll, G.; Jansz, P.; Khaghani, A.; Levy, W.C.; Wieselthaler, G.M. Multicenter Evaluation of an Intrapericardial Left Ventricular Assist System. J. Am. Coll. Cardiol. 2011, 57, 1375-1382. [CrossRef]

16. Krabatsch, T.; Netuka, I.; Schmitto, J.D.; Zimpfer, D.; Garbade, J.; Rao, V.; Morshuis, M.; Beyersdorf, F.; Marasco, S.; Damme, L.; et al. Heartmate 3 fully magnetically levitated left ventricular assist device for the treatment of advanced heart failure -1 year results from the Ce mark trial. J. Cardiothorac. Surg. 2017, 12, 1-8. [CrossRef]

17. Mehra, M.R.; Naka, Y.; Uriel, N.; Goldstein, D.J.; Cleveland, J.C.; Colombo, P.C.; Walsh, M.N.; Milano, C.A.; Patel, C.B.; Jorde, U.P.; et al. A Fully Magnetically Levitated Circulatory Pump for Advanced Heart Failure. N. Engl. J. Med. 2017, 376, 440-450. [CrossRef]

18. Rogers, J.G.; Pagani, F.D.; Tatooles, A.J.; Bhat, G.; Slaughter, M.S.; Birks, E.J.; Boyce, S.W.; Najjar, S.S.; Jeevanandam, V.; Anderson, A.S.; et al. Intrapericardial Left Ventricular Assist Device for Advanced Heart Failure. N. Engl. J. Med. 2017, 376, 451-460. [CrossRef]

19. Schramm, R.; Zittermann, A.; Morshuis, M.; Schoenbrodt, M.; von Roessing, E.; von Dossow, V.; Koster, A.; Fox, H.; HakimMeibodi, K.; Gummert, J.F. Comparing short-term outcome after implantation of the HeartWare HVAD and the Abbott HeartMate 3. ESC Heart Fail 2020, 7, 908-914. [CrossRef]

20. Mueller, M.; Hoermandinger, C.; Richter, G.; Mulzer, J.; Tsyganenko, D.; Krabatsch, T.; Starck, C.; Stein, J.; Schoenrath, F.; Falk, V.; et al. Retrospective 1-year outcome follow-up in 200 patients supported with HeartMate 3 and HeartWare left ventricular assist devices in a single centre. Eur. J. Cardio-Thorac. Surg. 2020, 57, 1160-1165. [CrossRef] 
21. Itzhaki Ben Zadok, O.; Ben-Avraham, B.; Shaul, A.; Hammer, Y.; Rubachevski, V.; Aravot, D.; Kornowski, R.; Ben-Gal, T. An 18-month comparison of clinical outcomes between continu-ous-flow left ventricular assist devices. Eur. J. Cardiothorac. Surg. 2019, 56, 1054-1061. [CrossRef]

22. Miller, L.W.; Guglin, M. Patient Selection for Ventricular Assist Devices. J. Am. Coll. Cardiol. 2013, 61, 1209-1221. [CrossRef] [PubMed]

23. Kirklin, J.K.; Pagani, F.D.; Goldstein, D.J.; John, R.; Rogers, J.G.; Atluri, P.; Arabia, F.A.; Cheung, A.; Holman, W.; Hoopes, C.; et al. American Association for Thoracic Surgery/International Society for Heart and Lung Transplantation guidelines on selected topics in mechanical circulatory support. J. Heart Lung Transplant. 2020, 39, 187-219. [CrossRef] [PubMed]

24. Potapov, E.V.; Antonides, C.; Crespo-Leiro, M.G.; Combes, A.; Färber, G.; Hannan, M.M.; Kukucka, M.; De Jonge, N.; Loforte, A.; Lund, L.H.; et al. 2019 EACTS Expert Consensus on long-term mechanical circulatory support. Eur. J. Cardio-Thorac. Surg. 2019, 56, 230-270. [CrossRef] [PubMed]

25. Maltais, S.; Davis, M.E.; Haglund, N. Minimally invasive and alternative approaches for long-term LVAD placement: The Van-derbilt strategy. Ann. Cardiothorac. Surg. 2014, 3, 563-569.

26. Maltais, S.; Anwer, L.A.; Tchantchaleishvili, V.; Haglund, N.A.; Dunlay, S.M.; Aaronson, K.D.; Pagani, F.D.; Cowger, J.; Salerno, C.T.; Shah, P.; et al. Left Lateral Thoracotomy for Centrifugal Continuous-Flow Left Ventricular Assist Device Placement: An Analysis from the Mechanical Circulatory Support Research Network. ASAIO J. 2018, 64, 715-720. [CrossRef]

27. El-Sayed Ahmed, M.M.; Aftab, M.; Singh, S.K.; Mallidi, H.R.; Frazier, O.H. Left ventricular assist device outflow graft: Alternative sites. Ann. Cardiothorac. Surg. 2014, 3, 541-545. [PubMed]

28. McGee, E., Jr.; Danter, M.; Strueber, M.; Mahr, C.; Mokadam, N.A.; Wieselthaler, G.; Klein, L.; Lee, S.; Boeve, T.; Maltais, S.; et al. Evaluation of a lateral thoracotomy implant approach for a centrifugal-flow left ven-tricular assist device: The LATERAL clinical trial. J. Heart Lung Transplant. 2019, 38, 344-351. [CrossRef] [PubMed]

29. Gosev, I.; Wood, K.; Ayers, B.; Barrus, B.; Knight, P.; Alexis, J.D.; Vidula, H.; Lander, H.; Wyrobek, J.; Cheyne, C.; et al. Implantation of a fully magnetically levitated left ventricular assist device using a ster-nal-sparing surgical technique. J. Heart Lung Transplant. 2020, 39, 37-44. [CrossRef] [PubMed]

30. Potapov, E.V.; Kukucka, M.; Falk, V.; Krabatsch, T. Off-pump implantation of the HeartMate 3 left ventricular assist device through a bilateral thoracotomy approach. J. Thorac. Cardiovasc. Surg. 2017, 153, 104-105. [CrossRef]

31. Hanke, J.S.; Rojas, S.V.; Cvitkovic, T.; Wiegmann, B.; Horke, A.; Warnecke, G.; Haverich, A.; Schmitto, J.D. First results of HeartWare left ventricular assist device implantation with tunnelling of the outflow graft through the transverse sinus. Interact. Cardiovasc. Thorac. Surg. 2017, 25, 503-508. [CrossRef] [PubMed]

32. Ozbaran, M.; Yagdi, T.; Engin, C.; Nalbantgil, S.; Ozturk, P. Left ventricular assist device implantation with left lateral thoracot-omy with anastomosis to the descending aorta. Interact. Cardiovasc. Thorac. Surg. 2018, 27, 186-190. [CrossRef]

33. Teuteberg, J.J.; Cleveland, J.C.; Cowger, J.; Higgins, R.S.; Goldstein, D.J.; Keebler, M.; Kirklin, J.K.; Myers, S.L.; Salerno, C.T.; Stehlik, J.; et al. The Society of Thoracic Surgeons Intermacs 2019 Annual Report: The Changing Landscape of Devices and Indications. Ann. Thorac. Surg. 2020, 109, 649-660. [CrossRef] [PubMed]

34. Milano, C.A.; Rogers, J.G.; Tatooles, A.J.; Bhat, G.; Slaughter, M.S.; Birks, E.J.; Mokadam, N.A.; Mahr, C.; Miller, J.S.; Markham, D.W.; et al. HVAD: The ENDURANCE Supplmental Trial. JACC Heart. Fail. 2018, 6, 792-802. [CrossRef]

35. Uriel, N.; Colombo, P.C.; Cleveland, J.C.; Long, J.W.; Salerno, C.; Goldstein, D.J.; Patel, C.B.; Ewald, G.A.; Tatooles, A.J.; Silvestry, S.C.; et al. Hemocompatibility-Related Outcomes in the MOMENTUM 3 Trial at 6 Months. Circulation 2017, 135, $2003-2012$. [CrossRef]

36. Mehra, M.R.; Goldstein, D.J.; Uriel, N.; Cleveland, J.C., Jr.; Yuzefpolskaya, M.; Salerno, C.; Walsh, M.N.; Milano, C.A.; Patel, C.B.; Ewald, G.A.; et al. Two-Year Outcomes with a Magnetically Levitated Cardiac Pump in HeartFailure. N. Engl. J. Med. 2018, 378, 1386-1395. [CrossRef] [PubMed]

37. Pae, W.E.; Connell, J.M.; Adelowo, A.; Boehmer, J.P.; Korfer, R.; El-Banayosy, A.; Hetzer, R.; Vigano, M.; Pavie, A. Does Total Implantability Reduce Infection With the Use of a Left Ventricular Assist Device? The LionHeart Experience in Europe. J. Hear. Lung Transplant. 2007, 26, 219-229. [CrossRef]

38. Pya, Y.; Maly, J.; Bekbossynova, M.; Salov, R.; Schueler, S.; Meyns, B.; Kassif, Y.; Massetti, M.; Zilbershlag, M.; Netuka, I. First human use of a wireless coplanar energy transfer coupled with a continu-ous-flow left ventricular assist device. J. Heart Lung Transplant. 2019, 38, 339-343. [CrossRef]

39. Selzman, C.H.; Koliopoulou, A.; Glotzbach, J.P.; McKellar, S.H. Evolutionary Improvements in the Jarvik 2000 Left Ventricular Assist Device. ASAIO J. 2018, 64, 827-830. [CrossRef]

40. Tarzia, V.; Di Giammarco, G.; Di Mauro, M.; Bortolussi, G.; Maccherini, M.; Tursi, V.; Maiani, M.; Bernazzali, S.; Marinelli, D.; Foschi, M.; et al. From bench to bedside: Can the improvements in left ventricular assist de-vice design mitigate adverse events and increase survival? J. Thorac. Cardiovasc. Surg. 2016, 151, 213-217. [CrossRef] [PubMed]

41. Eulert-Grehn, J.J.; Lanmüller, P.; Schönrath, F.; Solowjowa, N.; Müller, M.; Mulzer, J.; Kaufmann, F.; Starck, C.; Krabatsch, T.; Falk, V.; et al. Two implantable continuous-flow ventricular assist devices in a biventric-ular configuration: Technique and results. Interact. Cardiovasc. Thorac. Surg. 2018, 27, 938-942. [CrossRef] [PubMed] 
42. Lavee, J.; Mulzer, J.; Krabatsch, T.; Marasco, S.; McGiffin, D.; Garbade, J.; Schmitto, J.D.; Zimpfer, D.; Potapov, E.V. An international multicenter experience of biventricular support with HeartMate 3 ventricular assist systems. J. Heart Lung Transplant. 2018, 37, 1399-1402. [CrossRef] [PubMed]

43. Strueber, M.; Schmitto, J.D.; Kutschka, I.; Haverich, A. Placement of 2 implantable centrifugal pumps to serve as a total artificial heart after cardiectomy. J. Thorac. Cardiovasc. Surg. 2012, 143, 507-509. [CrossRef] [PubMed]

44. Lebreton, G.; Mastroianni, C.; Amour, J.; Leprince, P. Implantation of Two HVADs Used as a Total Artificial Heart: A New Ap-proach. Ann. Thorac. Surg. 2019, 107, e165-e167. [CrossRef] [PubMed] 